\title{
Immunohistochemical markers for arthritis in psoriasis
}

\author{
D J Veale, L Barnes, S Rogers, O FitzGerald
}

\begin{abstract}
Objectives-To examine the immunohistological features in the involved skin of patients with psoriatic arthritis (PA) $(n=15)$, compared with those in involved skin from patients with psoriasis but no arthritis $(n=5)$, and with a group with normal skin $(n=4)$, to identify markers for arthritis in psoriasis.
\end{abstract}

Methods-Skin was obtained from patients by $6 \mathrm{~mm}$ punch biopsy and normal skin was provided by the department of plastic surgery. Samples were stained with monoclonal antibodies against $T$ cells (CD3, CD8, CD4, CD45Ro), B cells (CD20), macrophages (mac387), vascular endothelium (FVIIIrelated antigen) and a Langerhan's cell marker (p155). The number of cells/ vessels staining with each monoclonal antibody was calculated and serial sections of skin were examined to estimate the presence of DR + keratinocytes.

Results-There were significantly more CD45Ro T-cells and blood vessels in patients with psoriatic arthritis compared with both psoriasis alone, and with normal controls $(p<0.02)$. While B-cells were not seen in psoriasis without arthritis or in normal skin, a small but significant number were observed in PA $(p<0 \cdot 02)$. Furthermore, while DR + keratinocytes were present in both psoriatic arthritis and psoriasis skin, there were significantly more DR + cells in the psoriatic arthritis epidermis compared with psoriasis alone $(\mathbf{p}<0.02)$.

Conclusions-This study suggests that increased numbers of CD45Ro T-cells, greater vascularity, the presence of $B$-cells, and increased numbers of DR + epidermal cells are markers for arthritis in patients with sporiasis.

St Vincent's Hospital, Dublin, Department of Rheumatology

D J Veale

O FitzGerald

Department of

Dermatology

$S$ Rogers`

The City of Dublin

Skin Cancer Hospital, $\star$

Dublin, Ireland

L Barnes

Correspondence to:

Dr O FitzGerald,

Dr O FitzGerald,

St Vincent's Hospital, El
Park, Dublin 4, Ireland.

Accepted for publication

7 March 1994 it is not possible to
develop an arthritis.

Immunohistological studies in Ps have demonstrated a number of characteristic findings: inflammatory cells, predominantly $\mathrm{T}$ lymphocytes, accumulate in the skin, ${ }^{4-6}$ there are prominent microvascular changes ${ }^{78}$ and keratinocytes (KCs) become highly activated. $^{9-11}$ The activated T lymphocyte expresses the antigen CD45Ro+, the class II MHC antigen HLA-DR+ and receptors all of which are important molecules in the recognition and binding of antigen peptide. ${ }^{12}$ Cell surface markers, including adhesion molecules such as intercellular adhesion molecule (ICAM-1), play important roles in cell-cell recognition, binding and communication necessary in the immune response. ${ }^{13}$ In contrast to the previously perceived role of $\mathrm{KCs}$ as being uninvolved in the inflammatory process, it is now known that they produce a number of proinflammatory cytokines and that they may express both MHC class II HLA-DR antigens as well as ICAM-1. ${ }^{10}$ Furthermore, it has been suggested that the presence of HLA-DR+ keratinocytes may be a marker for arthritis in psoriasis. ${ }^{14}$

In this study, a quantitative immunohistological examination of the involved skin from patients with psoriatic arthritis (PA) was undertaken. Results were compared with skin obtained from patients with psoriasis but no arthritis (Ps) and with normal control skin to identify markers for arthritis in psoriasis.

\section{Materials and methods}

PATIENT POPULATION

Patients with Ps and PA were recruited from outpatient clinics and as inpatients from the wards of the dermatology and the rheumatology services of the City of Dublin Skin and Cancer Hospital, Beaumont Hospital and St Vincent's Hospital, Dublin. This ensured that patients with a spectrum of mild to severe skin and joint disease were included in the study. Patients were required to satisfy the criteria of Moll and Wright for the diagnosis of PA; $;^{15}$ however, patients with a rheumatoid factor titre greater than 1:80 were excluded from the study. Patients who had taken diseasemodifying antirheumatic drugs or undergone psoriasis therapy within the three months before assessment were excluded. All patients gave their informed consent, and the study had the approval of the Ethics Committees of all three hospitals.

Skin biopsies were obtained from 15 patients with PA. There were eight females and the mean (range) age was 50 years (21-75). The mean (range) disease duration of psoriasis was 15 years $(0 \cdot 25-50)$ and of arthritis was seven years $(0 \cdot 25-24)$. All patients had psoriasis 
vulgaris, eight had an asymmetric oligoarthritis and seven had a symmetrical polyarthritis. Skin biopsies were also obtained from five patients with psoriasis but no arthritis (Ps) and from four normal control subjects. Extent and severity of psoriasis was evaluated in the percentage of skin involved using the rule of $9 \mathrm{~s}$. The median (range) in the PA group was $18 \%$ (9-72) and in the Ps group was 18\% (9-63) demonstrating that no significant difference existed in the skin disease between the two groups. Skin biopsies were obtained before the start of treatment of the skin disease.

\section{CLINICAL ASSESSMENT}

All patients were assessed by the same physician (DV). A full history was taken including previous therapy as an outpatient or inpatient. The distribution and percentage of skin involved by psoriasis was recorded and the presence of nail dystrophy and pattern of joint involvement was noted.

TECHNIQUE OF SKIN BIOPSY

Punch biopsy specimens, $6 \mathrm{~mm}$ in diameter, were obtained from the edge of a psoriatic plaque using local anaesthesia with $2 \%$ lignocaine. Normal control skin was provided by the department of plastic surgery from patients undergoing split skin grafts.

TISSUE PREPARATION

The biopsies were divided into two pieces, one of which was placed on sephadex and snap frozen in liquid nitrogen. Sections $5 \mu \mathrm{m}$ thick were then cut from the frozen specimens and placed on glass slides. Several sections from each biopsy were placed on each slide to obtain a representative assessment. They were dried at room temperature overnight, wrapped in tin-foil and then stored at $-70^{\circ} \mathrm{C}$ until processed. The remaining biopsy tissue was fixed in formalin and embedded in paraffin for haematoxylin and eosin, plasma cell and mast cell staining. Plasma cells were demonstrated using methyl green pyronin (MGP) stain and mast cells with a uronitrate metachromatic staining method.

IMMUNOHISTOCHEMICAL STAINING TECHNIQUE Tissue sections stored at $-70^{\circ} \mathrm{C}$ were allowed to thaw at room temperature before being unwrapped. The sections were then fixed in acetone for 10 minutes before staining. The monoclonal antibodies used are shown together with their respective antigens and specificities in table 1 .

A standard three-stage immunoperoxidase labelling technique utilising avidin-biotinimmunoperoxidase complex $(\mathrm{ABC})^{16}$ was employed. Colour was developed by immersing the slides in a solution of $0.05 \%$ (weight/volume) 3,3'-diaminobenzidine tetrahydrochloride (Sigma, St Louis, MO) and $0.003 \%$ hydrogen peroxide in $0.05 \mathrm{M}$ Tris$0 \cdot 15 \mathrm{M} \mathrm{NaCl}$ buffer, $\mathrm{pH} 7 \cdot 4$. Staining of serial
Table 1 Monoclonal antibodies: source, antigen recognised and respective specificity

\begin{tabular}{|c|c|c|c|}
\hline $\begin{array}{l}\text { Monoclonal } \\
\text { Antibody }\end{array}$ & Source & Antigen & Specificity \\
\hline $\begin{array}{l}\text { T3 } \\
\text { T4 } \\
\text { T8 }\end{array}$ & $\begin{array}{l}\text { DAKO } \\
\text { DAKO } \\
\text { DAKO }\end{array}$ & $\begin{array}{l}\mathrm{CD} 3 \\
\mathrm{CD} 4 \\
\mathrm{CD} 8\end{array}$ & $\begin{array}{l}\text { All T cells } \\
\text { Helper T cells } \\
\text { Suppressor/ } \\
\text { cytotoxic T cells }\end{array}$ \\
\hline $\begin{array}{l}\text { UCHL1 } \\
\text { Mac } 387 \\
\text { Leu-M3 } \\
\text { L26 } \\
\text { HLA-DR }\end{array}$ & $\begin{array}{l}\text { DAKO } \\
\text { DAKO } \\
\text { BD } \\
\text { DAKO } \\
\text { DAKO }\end{array}$ & $\begin{array}{l}\text { CD45Ro } \\
\text { L1 } \\
\text { CD14 } \\
\text { CD20 } \\
\text { Class II }\end{array}$ & $\begin{array}{l}\text { Memory T cells } \\
\text { Monocytes } \\
\text { Monocytes } \\
\text { B cells } \\
\text { B cells/ } \\
\text { Activated T cells }\end{array}$ \\
\hline $\begin{array}{l}\text { FVIII-Rag } \\
\text { p155 }\end{array}$ & $\underset{\star}{\mathrm{DAKO}}$ & $\begin{array}{l}\text { FVIII-Rag } \\
\text { Unknown }\end{array}$ & $\begin{array}{l}\text { Endothelial cells } \\
\text { Monocytes/ } \\
\text { Langerhans cells }\end{array}$ \\
\hline
\end{tabular}

sections of skin was undertaken using antiHLA-DR, anti-CD3 and the monoclonal p155 which recognises monocyte-derived phagocytic cells ${ }^{17}$ such as dendritic Langerhan's cells. A patient was considered to have HLA-DR+ keratinocytes if cells were HLA-DR+ and CD3/p155 negative.

Tonsillar tissue was used for immunohistological controls; the positive controls were processed in exactly the same way as the skin and the primary antibody was replaced by PBS for the negative controls.

MICROSCOPIC EVALUATION

All sections of tissue were examined under $400 \times$ magnification using a Leitz Dialux 20 microscope by DV. The total number of cells was counted for each monoclonal using a 1 $\mathrm{mm}$ Indx graticule (Graticules Ltd, Tonbridge, Kent, UK) and the number of blood vessels was counted per high power field. The number of cells and blood vessels per $\mathrm{mm}^{2}$ of tissue was then calculated. Only sections in which both the epidermis and the dermis were identified were assessed. A coefficient of variation of less than $8 \cdot 80 \%$ was obtained for the quantification of cell types and blood vessels.

STATISTICAL ANALYSIS

Differences between the mean number of cells and vessels in the tissues were assessed using the Wilcoxon signed rank test. Correlations were calculated using Spearman rank coefficient of correlation.

\section{Results}

INCREASED B-CELLS IN THE INFILTRATE OF

PATIENTS WITH PA

There was a B-cell infiltrate demonstrated in the dermis of 14 of the 15 patients with PA. In one patient, B-cells were identified infiltrating the epidermis from a dermal papillae (fig 1). No B-cells were present in the dermis in four out of five controls with Ps or in any of the controls with normal skin. A small number of B-cells was present in the skin biopsy of one patient with Ps. The mean (SE) number of cells per $\mathrm{mm}^{2}$ of B-cells in the dermal infiltrate was significantly greater in PA compared with Ps and with normal controls [15.9 (4.3) v 1.5 


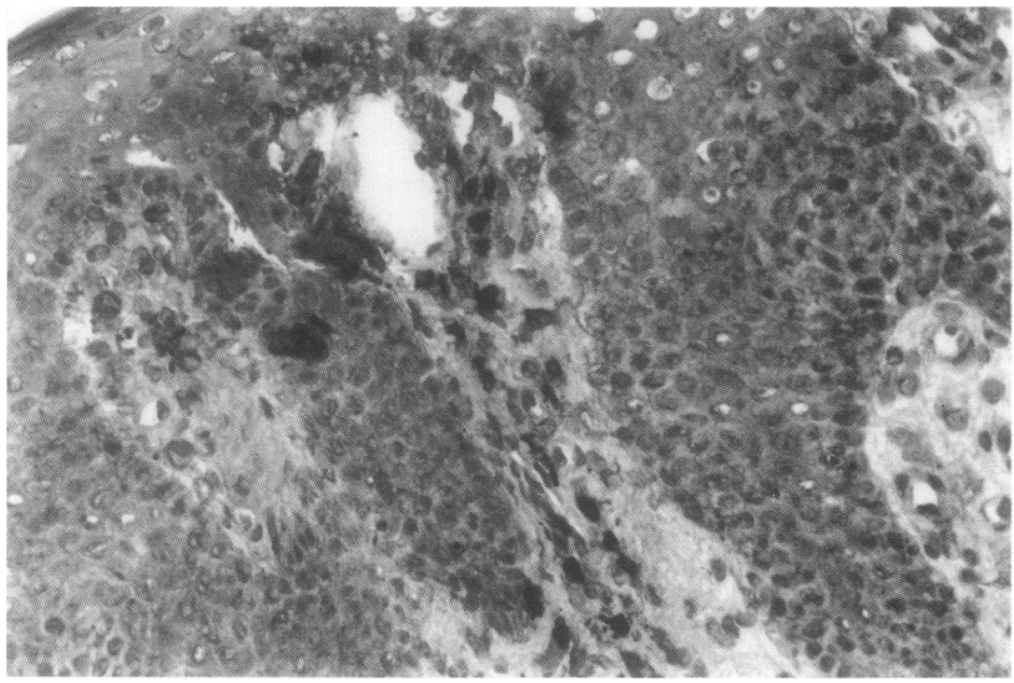

Figure 1 Section of involved skin from a patient with psoriatic arthritis showing CD20 B cells infiltrating the epidermis from the dermal papillae. (Original magnification $\times 400$ ).

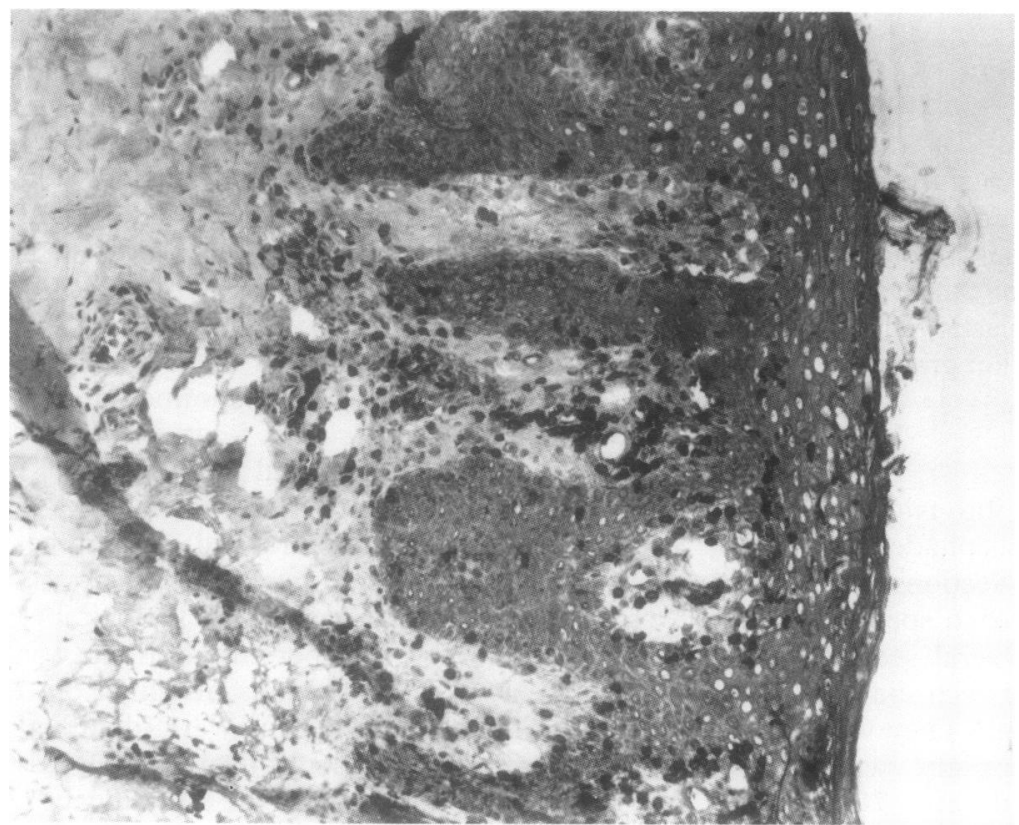

Figure 2 Section of involved skin from a patient with psoriatic arthritis showing CD4 $+T$ cells infiltrating the epidermis and dermis. (Original magnification $\times 250$ ).

$(1 \cdot 4) ; p=0 \cdot 02]$. The relationship between the presence of B-cells in the dermal infiltrate and arthritis is shown in table 2 . Finally, using the plasma cell marker MGP, an occasional plasma cell was demonstrated in the dermal infiltrate in patients with PA while no plasma cells were noted in Ps or in the normal control specimens.

INCREASED CD45RO T-CELLS IN PA

T-cells, as demonstrated by the CD3 marker, were the most abundant inflammatory cells in the dermal infiltrate of both Ps and PA. Most of these cells were also CD4+ (fig 2) and CD45Ro+ indicating that they were memory $T$-cells. In comparison to Ps, the patients with PA had significantly more CD45Ro $T$ cells $\mathrm{mm}^{2}$ [mean (SE), 396.6 (176.4) v 161.5 $(37 \cdot 6) ; p=0.02]$. Most of the remaining mononuclear cells were monocyte/macrophage in origin as they stained positive with the
Table 2 Relationship between the presence of dermal $B$-cells and arthritis

\begin{tabular}{|c|c|}
\hline Patients (n) & $\begin{array}{l}\text { B-cell infiltrate in involved skin } \\
\text { present }\end{array}$ \\
\hline $\begin{array}{l}\text { PA (15) } \\
\text { Ps (5) } \\
\text { Normal (4) }\end{array}$ & $\begin{array}{c}14 \dagger \\
1 \\
0\end{array}$ \\
\hline
\end{tabular}

tp $=0.02$.

Table 3 Epidermal HLA-DR+ cells in PA, Ps and normal controls

\begin{tabular}{lcl}
\hline Patients (total No) & \multicolumn{2}{c}{ Epidermal $H L A-D R+$ cells } \\
& \multicolumn{3}{c}{ Cells/mm (SE) $^{2}$} \\
\hline PA (15) & $161 \cdot 7$ & $(25 \cdot 7)^{\star}$ \\
Ps (5) & $90 \cdot 9$ & $(18)$ \\
Normal (4) & $149 \cdot 2$ & $(41 \cdot 8)$ \\
\hline
\end{tabular}

${ }^{\star} \mathrm{p}=0.02$ PA vs Ps.

Mac387, p155 and CD14 monoclonal antibodies. There was no significant difference in the number of monocytes between psoriatic patients with and without arthritis.

HLA-DR+ KERATINOCYTES OCCUR BOTH IN PA AND IN PS

While there were significantly more HLA$\mathrm{DR}+$ cells $/ \mathrm{mm}^{2}$ in PA epidermis compared with Ps $[161.7(25.7) v 90.9$ (18); $\mathrm{p}=0.02)$, there was no significant difference in the number of HLA-DR+ cells $/ \mathrm{mm}^{2}$ in PA epidermis compared with the normal controls (table 3). To assess which epidermal cells were HLA-DR+, serial sections of skin from three patients with PA and three controls with Ps were examined using a marker for HLA-DR, CD3 and the Langerhan's cell marker p155. HLA-DR+ cells which were negative for CD3 and p155 and thus consistent with keratinocytes were demonstrated in the epidermis from involved skin in patients with PA (fig 3) as well as in patients with Ps (fig 4).

VASCULARITY IN PA AND PS

The number of blood vessels was assessed in all sections of skin and the mean number of vessels per $\mathrm{mm}^{2}$ of tissue calculated. There were significantly more blood vessels in PA and Ps skin compared with normal controls [PA: 112 (17), Ps: 77 (18), Controls: 51 (7); $p=0.02]$. The number of vesseis in the patients with PA tended to be greater than in Ps although the difference did not reach statistical significance.

\section{Discussion}

In this study, a small but significant number of $B$ cells was demonstrated in the involved skin of $14 / 15$ patients with PA. In contrast, no B cells were found in 4/5 patients with $P s$ or in 4/4 normal control skin specimens. While CD4 + CD45Ro+ T-cells accounted for the majority of cells in the dermal infiltrate in both PA and Ps, there were significantly greater numbers of activated $T$ cells in PA skin compared to Ps and to normal controls. 

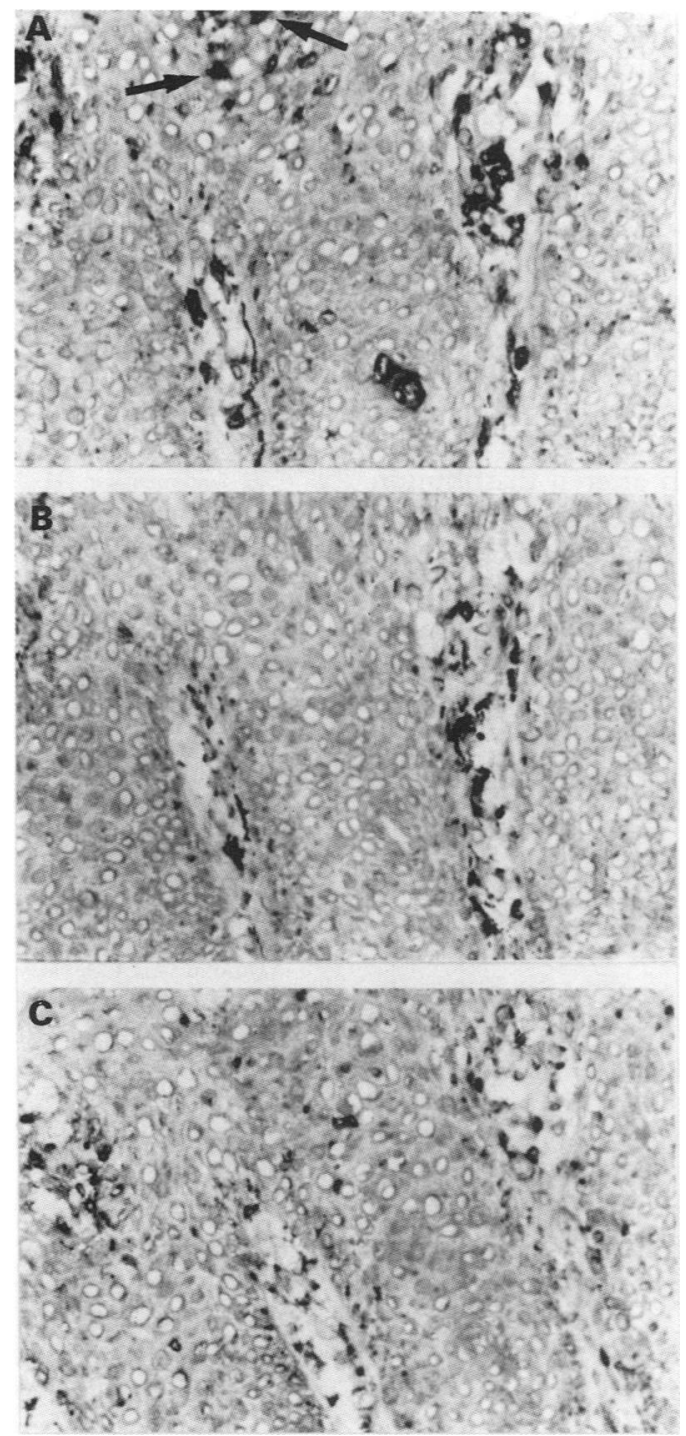

Figure 3 Serial sections of involved skin from a patient with psoriatic arthritis stained with monoclonal antibodies to show (A) HLA-DR+ cells, (B) Langerhan's cells and (C) CD3 T cells. In (A) there are numerous cells in the epidermis staining positive for HLA-DR (arrows), which are 155 and $C D 3$ negative ( $B$ and $C$ ). The staining of Langerhan's cells in $(B)$ is concentrated at the dermoepidermal junction. $T$ cells stained with $C D 3$ in $(C)$ are scattered throughout the dermis and epidermis. Epidermal cells staining DR+ and negative with 155 and $C D 3$ are $D R+$ keratinocytes. (Original magnification $\times 400$ ).

Furthermore, in a subgroup of patients in which serial sections of skin were examined, HLA-DR+ keratinocytes were identified in the epidermis of psoriasis patients with or without arthritis. Finally, the number of dermal blood vessels was significantly increased in both PA and Ps patients compared with controls.

The finding of a sparse B cell infiltrate with some plasma cells in PA skin is interesting. Psoriasis is not generally associated with B cell hyperactivity although autoantibody production has been reported. ${ }^{18} 19$ Indeed, PA is characterised by the absence of rheumatoid factor in the serum helping to distinguish the condition from rheumatoid arthritis (RA). However, B cells with plasma cells are abundant in PA synovium where they may form focal infiltrates similar to those seen in RA. ${ }^{20}$ Thus B cells do appear to play a role in $\mathrm{PA}$ and further studies of $\mathrm{B}$ cell function could prove rewarding.

A

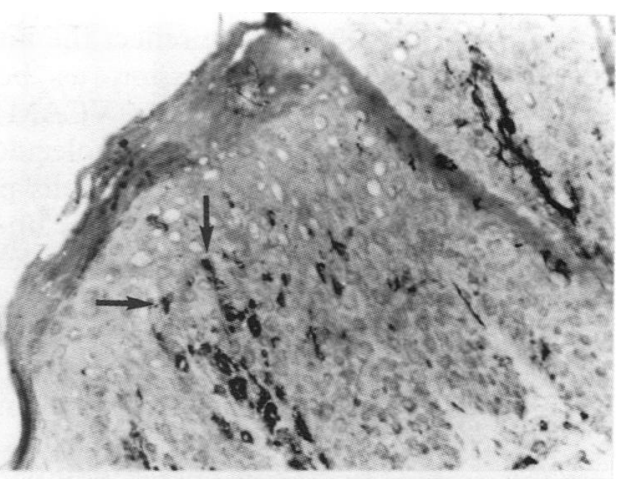

B
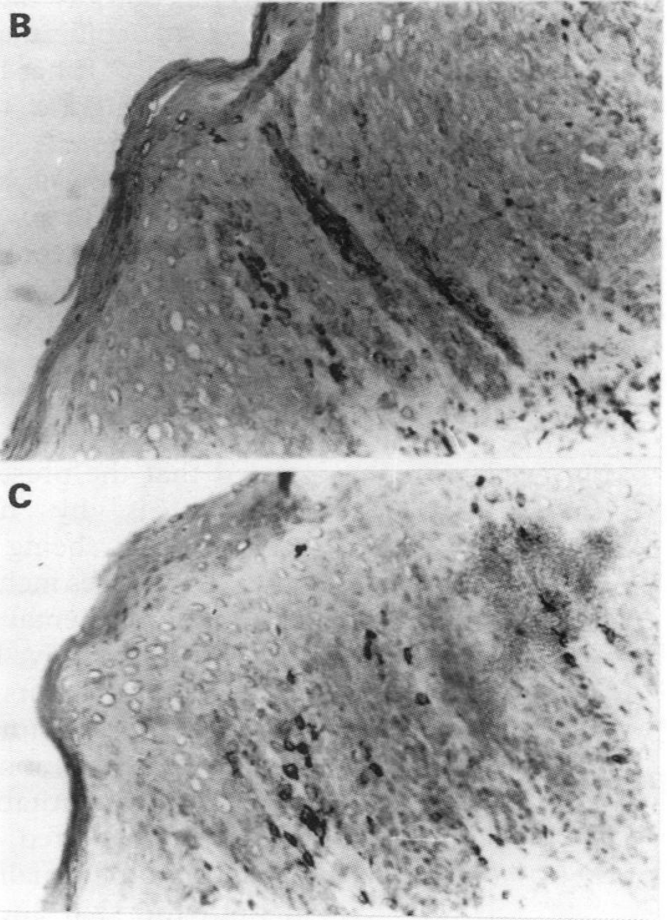

Figure 4 Serial sections of involved skin from a patient with psoriasis but no arthritis stained with monoclonal antibodies to show (A) HLA-DR+ cells, (B) Langerhan's cells and $(C) C D 3 T$ cells. In $(A)$ there are numerous cells in the epidermis staining positive for $H L A-D R$ (arrows), which are $p 155$ and $C D 3$ negative $(B$ and $C)$. Again Langerhan's cells are staining predominantly at the dermoepidermal junction and $T$ cells are scattered throughout the dermis and epidermis. (Original magnification $\times 250$ ).

$T$ cells, predominantly $\mathrm{T}$ helper (CD4+) cells, have previously been described to represent the majority of the cells in the dermal infiltrate in $\mathrm{Ps}^{4-614}$ and may persist in the chronic psoriatic plaque. ${ }^{6}$ Many $T$ cells in psoriatic skin express the class II HLA-DR antigen and these cells have been shown to increase in the dermis and infiltrate the epidermis during early development of a psoriatic lesion. ${ }^{5}$ Further evidence for $\mathrm{T}$ cell involvement in the pathogenesis of psoriasis is suggested by the observations that cyclosporin A, a drug which inhibits $T$ cell activation, may lead to remission of the skin disease ${ }^{21}$ and clearance of severe psoriasis has been described after allogenic bone marrow transplantation. ${ }^{22}$ In the present study, the findings confirm previous reports of a predominant $T$ cell infiltrate, these cells expressing the HLA-DR and CD45Ro antigens indicating that they are memory $T$ cells in a post-activation state. Greater numbers of CD4 + CD45Ro+ T cells are seen in PA skin compared with Ps and this 
may reflect the intensity of adhesion molecule expression as both vascular cell adhesion molecule (VCAM)-1 and endothelial leucocyte adhesion molecule (ELAM)-1 appear to bind memory $T$ cells preferentially ${ }^{23}$ and the latter is known to be up-regulated in psoriatic skin. ${ }^{24}$

Langerhan's cells are found in normal skin forming a close network of interdigitating cells in the stratum Malpighii. It was initially suggested that the number of Langerhan's cells was increased in psoriasis. ${ }^{514}$ However, a number of studies have now shown a reduction in overall number and an altered distribution pattern of epidermal Langerhan's cells in psoriasis. ${ }^{4526}$ It has been suggested that these cells now migrate to the dermo-epidermal junction. ${ }^{26}$ More recently, it has been suggested that there is a marked increase in the frequency of PA in psoriasis patients whose keratinocytes express HLA-DR antigen, identified as epidermal cells staining with a monoclonal for HLA-DR but not for OKT $6 .{ }^{1+}$ The possibility that some of these cells might represent activated $T$ cells or B cells was not considered. Previous studies have demonstrated that the presence of HLA-DR+ keratinocytes is by no means specific to psoriasis $^{111427}$ being found in a number of other dermatoses including lymphocytic vasculitis, lupus erythematosus, morphea and many more. In this study, HLA-DR+ keratinocytes are seen in patients both with PA and Ps although more abundant in those with PA. Thus the association of $\mathrm{DR}+$ keratinocytes with PA is quantitative and not absolute as previously suggested.

Vascular abnormalities have been described in both the skin and synovium in psoriasis. Braverman extensively examined the microcirculation in psoriatic skin and described prolongation and dilatation of the dermal capillary loops. ${ }^{7}$ In addition, ultrastructural abnormalities in the blood vessels were seen on electron microscopy with the development of venous-like capillaries with bridged fenestrations. ${ }^{8}$ Similar changes in vascularity have been described in the synovial membrane in PA. ${ }^{28}$ These studies, however have not been quantitative and a comparison of the vascularity of PA and Ps skin has not been previously undertaken. In this study, psoriatic skin is shown to be more vascular compared with control specimens with a trend towards more blood vessels in the skin from PA subjects compared with those with psoriasis alone.

In conclusion, the present study has identified quantitative immunohistochemical differences in the skin from patients with PA compared with skin from patients with psoriasis alone. It is suggested that the presence of a B-lymphocytic infiltrate, increased CD45Ro $T$-lymphocytes and increased HLA-DR + keratinocytes are indicators of a more active inflammatory process and act as markers for arthritis in psoriasis.
This study was funded by a grant from The Charitable Infirmary Charitable Trust.

1 Farber E M, Nall L. Epidemiology in psoriasis research Hawaii Med f 1982; 41: 430-9.

2 Leczinsky C G. The incidence of arthropathy in a ten-year series of psoriasis cases. Acta Dermatol Vencr (Sth) 1948 28: 483-7.

3 Hellgren L. Association between rheumatoid arthritis and psoriasis in total populations. Acta Rhctum Scand 1969; 15: 316-26.

4 Bos J D, Huslebosch H J, Krieg S R, Bakker P M, Cormane R H. Immunocompetent cells in Psoriasis. Arch Dermatol Res 1983; 275: 181-9.

5 Baker B S, Swain A F, Fry L, Valdimarsson H. Epidermal T lymphocytes and HLA-DR expression in psoriasis. $B$ Dermatol 1984; 110: 555-64

6 Baker B S, Swain A F, Griffiths C E M, Leonard J N, Fry $L$, Valdimarsson $H$. Epidermal $T$ lymphocytes and dendritic cells in chronic psoriasis: the effects of PUVA treatment. Clin Exp Immunol 1985; 61: 526-34.

7 Braverman I M. Electron microscopic studies of the microcirculation in psoriasis. F Invest Dermatol 1972; 59 $91-8$

8 Braverman I M, Yen A. Microcirculation in psoriatic skin. f Invest Dermatol 1974; 62: 493-502.

9 Barker J N W N, Jones M L, Swenson C L, et al. Monocyte chemotaxis and activating factor (MCAF) production by keratinocytes in response to interferon-gamma. 7 Immumol 1991; 146: 1192-7.

10 Nickoloff B J, Karabin G D, Barker J N, ot al. Cellular ocalisation of IL-8 and it's inducer tumour necrosis factor-alpha in psoriasis. Am f Pathol 1991; 138: 129-40.

11 Aubock J, Romani N, Grubauer G, Fritsch P. HLA-DR expression by keratinocytes is a common feature of diseased skin. Br f Dermatol 1986; 114: 467-72.

12 Moretta A, Mingari M C, Corte G, Moretta L. Receptors of immunoglobulins and activation markers on human T lymphocytes. Clin Haematol 1982; 11: 679

13 Dougherty G J, Murdoch S, Hogg N. The function of intercellular molecule-1 (ICAM-1) in the generation of the immune response. Eur F Immunol 1988; 18: 35-9.

14 Gottlieb A B, Lifshitz B, Shu Man Fu, Staiano-Coico I, Y Wang C, Carter D M. Expression of HLA-DR molecules by keratinocytes, and the presence of Langerhans cells in the dermal infiltrate of active psoriatic plaques. $7 \mathrm{Fxp} \mathrm{Mcd}$ the dermal infiltrate of

15 Moll J M H, Wright V. Psoriatic Arthritis. Scmin Arthritis Rheum 1973; 3: 55-78

16 Hsu S M, Raine L, Fanger H. Use of avidin-biotinimmunoperoxidase complex (ABC) in immunoperoxidase techniques: a comparison between $\mathrm{ABC}$ and unlabelled antibody (PAP) procedures. 7 Histochen Cytochem 1981; 29: 577-80.

17 Morganelli P M, Guyre J M. IFN-gamma plus glucocorticoids stimulate the expression of a newly identified human mononuclear phagocyte-specific antigen. F Immumol 1988; 140: 2296-304

18 Sany J, Clot J. Immunological abnormalities in psoriatic arthropathy. 7 Rheunatol 1980; 7: 438-44.

19 Laurent M R, Panayi G S, Shepherd P. Circulating immune complexes, serum immunoglobulins and acute phase proteins in psoriasis and psoriatic arthritis. Ann Rheum Dis 1981; 40: 66-9.

20 Veale D, Yanni G, Rogers S, Barnes L, Bresnihan B, FitzGerald O. Reduced synovial membrane macrophage numbers, ELAM-1 expression and lining layer hyperplasia in psoriatic arthritis as compared with rheumatoid arthritis. Arthritis Rheum 1993; 36: 893-900.

21 Griffiths C E M, Powles A V, Leonard J N, Fry L Baker B S, Valdimarsson H. Clearance of psoriasis with low dose cvclosporin. BMF 1986; 293: 731-2.

22 Eedy D J, Burrows D, Bridges J M, Jones F G C. Clearance of severe psoriasis after allogenic bone transplantation. BM7 1990; 300: 908.

23 Shimizu Y, Shaw S, Graber N, et al. Activation independent adhesion of human memory $T$ cells to adhesion adhesion of human memory $T$ cell

24 Groves R W, Allen M H, Barker J N W N, Haskard D O, MacDonald D $M$. Endothelial leucocyte adhesion molecule-1 (ELAM-1) expression in cutaneous inflammation. Brf Dermatol 1991; 124: 117-23.

25 Lisi P. Investigation on Langerhan's cells in pathological human epidermis. Acta Dermatol Vencreol (Stockh) 1973 53: $425-8$.

26 Alegre V A, MacDonald D M, Poulter L W. The simultaneous presence of Langerhan's cells and interdigitating cell antigenic markers on inflammatory dendritic cells. Clin Exp Immunol 1986; 64: 330-3.

27 Griffiths C E M, Voorhees J J, Nickoloff B J Characterisation of intercellular adhesion molecule- 1 and HIA-DR in normal and inflamed skin: modulation an interferon-gamma and tumor necrosis factor. $\mathcal{F} \mathrm{Am} \mathrm{Acad}$ interferon-gamma and tum

28 Espinoza L R, Vasey F B, Espinoza C G, Bocanegra T S, Germain B F. Vascular changes in psoriatic synovium. Arthritis Rheum 1982; 25: 677-84. 